\title{
EFFECT OF DEPTH-DEPENDENT TARGET STRENGTH ON BIOMASS ESTIMATION OF JAPANESE ANCHOVY
}

Hiroto Murase

The Institute of Cetacean Research, 4-5 Toyomi-cho, Chuo-ku, Tokyo 104- 0055, Japan., murase@cetacean.jp

Atsushi Kawabata

National Research Institute of Fisheries Science, 2-12-4 Fukuura, Kanazawa, Yokohama, Kanagawa 236-8648, Japan.

Hiroshi Kubota

National Research Institute of Fisheries Science, 2-12-4 Fukuura, Kanazawa, Yokohama, Kanagawa 236-8648, Japan.

Masayasu Nakagami

Hachinohe Branch, Tohoku National Fisheries Research Institute, 25-259 Shimo-mekurakubo, Hachinohe-shi, Aomori 031-0841, Japan.

Kazuo Amakasu

Tokyo University of Marine Science and Technology, 4-5-7 Konan, Minato, Tokyo 108-8477, Japan.

See next page for additional authors

Follow this and additional works at: https://jmstt.ntou.edu.tw/journal

Part of the Aquaculture and Fisheries Commons

\section{Recommended Citation}

Murase, Hiroto; Kawabata, Atsushi; Kubota, Hiroshi; Nakagami, Masayasu; Amakasu, Kazuo; Abe, Koki; Miyashita, Kazushi; and Oozeki, Yoshioki (2011) "EFFECT OF DEPTH-DEPENDENT TARGET STRENGTH ON BIOMASS

ESTIMATION OF JAPANESE ANCHOVY," Journal of Marine Science and Technology. Vol. 19: Iss. 3, Article 5. DOI: 10.51400/2709-6998.2191

Available at: https://jmstt.ntou.edu.tw/journal/vol19/iss3/5

This Research Article is brought to you for free and open access by Journal of Marine Science and Technology. It has been accepted for inclusion in Journal of Marine Science and Technology by an authorized editor of Journal of Marine Science and Technology. 


\section{EFFECT OF DEPTH-DEPENDENT TARGET STRENGTH ON BIOMASS ESTIMATION OF JAPANESE ANCHOVY}

\section{Acknowledgements}

We express thanks to all of the researchers and crews who were engaged in the survey. Comments from two anonymous reviewers and the guest editor, Dr. Masahiko Furusawa, greatly improved the contents of the manuscript. This survey was supported by the Fisheries Agency of Japan, the Fisheries Research Agency of Japan and the Institute of Cetacean Research. We thank these institutions for their support. The results of this paper was initially presented to the Asian Fisheries Acoustics Society (AFAS) 2009 meeting "The International Conference on Fisheries Acoustics and Contribution for Sustainable Fisheries in Asia". We express thanks to the conveners of the meeting who provided us such opportunity.

\section{Authors}

Hiroto Murase, Atsushi Kawabata, Hiroshi Kubota, Masayasu Nakagami, Kazuo Amakasu, Koki Abe, Kazushi Miyashita, and Yoshioki Oozeki 


\title{
EFFECT OF DEPTH-DEPENDENT TARGET STRENGTH ON BIOMASS ESTIMATION OF JAPANESE ANCHOVY
}

\author{
Hiroto Murase*, Atsushi Kawabata**, Hiroshi Kubota**, Masayasu Nakagami***, \\ Kazuo Amakasu****, Koki Abe*****, Kazushi Miyashita******, \\ and Yoshioki Oozeki*
}

Key words: abundance, Engraulis japonicus, pelagic fish.

\begin{abstract}
Effect of the depth-dependent target strength (TS) on biomass estimation of Japanese ahcovy was examined by using following four $T S$ models: (1) $T S=20 \log L_{t}-71.9$, (2) $T S=$ $20 \log L_{t}-72.5$, (3) $T S=20 \log L_{t}-(20 / 3) \log (1+z / 10)-67.6$ and (4) $T S=20 \log L_{t^{-}}(20 / 3) \log (1+z / 10)-64.7$, where $L_{t}$ and $z$ represent total length (cm) and depth (m), respectively. (1) and (2) have been used in conventional fisheries resources surveys; (3) and (4) take account of depth-dependent TS. Because (1)-(3) were based on in-situ measurement, pitch angles of individuals used in the models were not known. Pitch angle is assumed $0^{\circ}$ $\left( \pm 10^{\circ}\right.$ std) in (4). Biomass estimated by (3) was $82 \%$ and $73 \%$ of (1) and (2), respectively. Biomass estimated by (3) was $195 \%$ of (4). The results indicated that the effect of the pitch angle on the biomass estimation could be large even if the effect of the depth-dependent $T S$ was taken account. Mean distribution depth can be used as a value for $z$.
\end{abstract}

\section{INTRODUCTION}

Understanding of abundance/biomass of target species is a

Paper submitted 03/27/10; revised 07/07/10; accepted 07/16/10. Author for correspondence: Hiroto Murase (e-mail: murase@cetacean.jp).

*The Institute of Cetacean Research, 4-5 Toyomi-cho, Chuo-ku, Tokyo 1040055, Japan.

**National Research Institute of Fisheries Science, 2-12-4 Fukuura, Kanazawa, Yokohama, Kanagawa 236-8648, Japan.

***Hachinohe Branch, Tohoku National Fisheries Research Institute, 25-259 Shimo-mekurakubo, Hachinohe-shi, Aomori 031-0841, Japan.

****Tokyo University of Marine Science and Technology, 4-5-7 Konan, Minato, Tokyo 108-8477, Japan.

*****National Research Institute of Fisheries Engineering, 7620-7 Hasaki, Kamisu, Ibaraki 314-0408, Japan.

******Field Science Center for the Northern Biosphere, Hokkaido University, 3-1-1 Minato, Hakodate, Hokkaido 041-8611, Japan. crucial requirement for fisheries management. Target strength (TS) plays important role in fisheries acoustic surveys to convert acoustic data to amount of fish. Japanese anchovy (Engraulis japonicas) is a small pelagic fish distributed in wide area of Asian waters [27]. Japanese anchovy is commercially harvested species [5]. In addition, Japanese anchovy plays important role in marine ecosystem as a prey of higher trophic predators such as skipjack tuna (Katsuwonus pelamis) [24] and cetaceans [16]. Given the importance, many acoustic surveys of Japanese anchovy were carried out in Asian waters $[12,15,17-20,23,28,30]$. Some paper used a $T S$ model reported by Iversen [12]. In other case, a TS model of clupeoids reported in Foote [6] was used as a substitution for $T S$ of Japanese anchovy (Murase unpublished data).

It was reported that $T S$ of a clupeoid fish, herring (Clupea harengus), decreased in accordance with increase in water depth because of the compression of the swimbladder by water pressure [10, 21]. Recently, depth-dependent change in $T S$ of Japanese anchovy was also reported [22, 31]. In addition, depth-dependent $T S$ of Japanese anchovy was examined based on a data set measured in an experimental tank [1]. However, effect of the depth-dependent $T S$ on biomass estimation of Japanese anchovy had not been examined fully. In this paper, the effect of the depth-depend TS on biomass estimation of Japanese anchovy is investigated by using a field data set collected in the offshore region of the western North Pacific.

\section{MATERIALS AND METHODS}

A fisheries acoustic survey was conducted in the western North Pacific in early summer in 2004 as a part of the Japanese Whale Research Program under Special Permit in the western North Pacific Phase II (JARPN II) (Fig. 1). The acoustic survey was conducted from 14 May to 8 June. Zigzag tracklines were set within the survey area. A research vessel, Kyoshin-maru \#2 (KS2, 372 GT, Kyodo Senpaku Ltd.) carried out the acoustic survey in daytime. A vertically oriented quantitative echosounder, EK500 (Simrad, Norway), with 


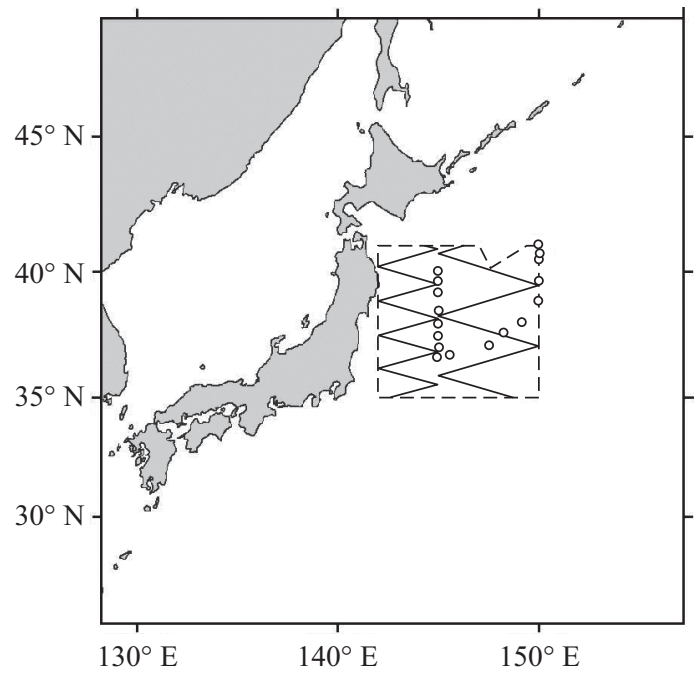

Fig. 1. Survey area (dotted line), planned trackline of acoustic survey (solid line) and trawl sampling stations (circles). The survey was conducted in the western North Pacific in early summer in 2004.

operating frequency of $38 \mathrm{kHz}$ was used to collect acoustic data. The transducer was hull-mounted with draft depth of 4 m. KS2 steamed on traklines with nominal speed of 10 knots. Biological samples were collected by a surface trawl, NST-99 (Nichimo, Japan) [26] onboard Hokuho-maru (HOK, 664 GT, Hokkaido). The surface trawl survey was conducted by Tohoku National Fisheries Research Institute for the purpose of stock assessment of Pacific saury (Cololabis saira). The acoustic and trawl surveys were conducted independently. The trawl was $86.3 \mathrm{~m}$ long with a mouth opening of $30 \times 30 \mathrm{~m}$ and a $6.0 \mathrm{~m}$ codend with a $17.5 \times 17.5 \mathrm{~mm}$ mesh inner. The trawl was towed for 60 minutes at each station. The nominal towing speed was 5 knots. Sampling depth was 0-20 m. Sampling was conducted at predetermined stations in daytime from 12 to 17 June.

Acoustic data were analyzed by using a software, Echoview version 3.5 (Myriax, Australia). Though it is known that most of Japanese anchovy is distributed in shallow water depth (e.g. less than $50 \mathrm{~m}$ ), it is distributed deeper than $50 \mathrm{~m}$ based on the unpublished data of the authors of this paper as well as scientific literatures $[25,29]$. Maximum water depth reported in a scientific literature was $150 \mathrm{~m}$ [25]. Based on the information on the vertical distribution pattern of Japanese anchovy, acoustic data from $7 \mathrm{~m}$ to $150 \mathrm{~m}$ were used in the analysis. Water depth less than $7 \mathrm{~m}$ could not be surveyed by the hullmounted echosounder. Japanese anchovy, Japanese sardine (Sardinops melanostictus) and mackerels (including both chub, Scomber japonicas, and blue, S. australasicus, mackerels) were only small pelagic fish species to form dense schools in the survey area. Backscatterings from pelagic fishes were distinguished from others based on the shapes and other auxiliary acoustic characteristics $[7,14,20]$ by experienced researchers. However, because species compositions in the schools could not be identified, proportion of species compo- sition by number of individuals was obtained using trawl data.

Nautical area scattering coefficient $\left(\mathrm{m}^{2} /\right.$ n.mile $\left.{ }^{2}, s_{A}\right)$ in every $1 \mathrm{n}$.mile by 1, 5, 10,50 $\mathrm{m}$ and $150 \mathrm{~m}$ depth bin was calculated by using Echoview. An echogram displayed by Echoview can be considered as a matrix. Distance can be considered as columns while depth can be considered as rows. Bin can be defined as depth of each raw. For instance, $50 \mathrm{~m}$ depth bins from 0 to $150 \mathrm{~m}$ water depth are consisted of three depth bins: 0-50 m, 50-100 $\mathrm{m}$ and 100-150 m. The depth bins assumed to be used in conventional echosounder surveys were selected in this paper. Then $s_{A}$ was converted to biomass density $(\rho)$, as $\rho=\left(s_{A} / \sigma\right) W_{t}$, where $\sigma$ and $W_{t}$ are acoustic scattering cross section and wet weight $(\mathrm{g})$ of a Japanese anchovy, respectively. Acoustic scattering cross section is derived as $\sigma=4 \pi 10^{0.1 T S}$ where $T S$ is target strength (dB). Following four TS-length models were used in this analysis: (1) $T S=20 \log L_{t}-71.9$ [6], (2) $T S=20 \log L_{t}-72.5$ [12], (3) $T S=20 \log L_{t}-(20 / 3) \log (1+$ $z / 10)-67.6$ [31] and (4) $T S=20 \log L_{t}-(20 / 3) \log (1+z / 10)-64.7$ [1], where $L_{t}$ is total length $(\mathrm{cm})$ and $z$ is water depth $(\mathrm{m})$ corresponding to distribution of Japanese anchovy. Depthdependence was not considered in models (1) and (2) and they have been used in conventional surveys. Depth-dependence was considered in models (3) and (4). Because models (1), (2) and (3) were based on field (in-situ) data, pitch angles of individuals used in the models were not known. Model (4) is based on the measurement in an experimental tank assuming a normal distribution with a mean pitch angle of $0^{\circ}$ and a standard deviation of $10^{\circ}, \mathrm{N}\left(0^{\circ}, 10^{\circ}\right)$. The pitch angle is not a field measurement value but an assumed value in daytime [1]. Depth-dependence considered in model (4) is same as model (3). Model (1) is for clupeoids while the rest of three are for Japanese anchovy. Mean $L_{t}$ and corresponding $W_{t}$ in the survey area were used in the analysis. Because scale length (from the most anterior part of the fish to the most posterior part covered by scale, $L_{s}$ ) was measured in the field, $L_{s}$ was converted to $L_{t}$ by using following equation: $L_{t}=1.1 L_{s}+0.8\left(\mathrm{R}^{2}=\right.$ 0.98) (Kawabata unpublished data). $W_{t}$ was estimated as $W_{t}=$ $0.04 L_{t}^{2.3}\left(\mathrm{R}^{2}=0.53\right)$ based on the field data. Model (4) is originally written for $L_{s}$. The model was rewritten for $L_{t}$ in this paper for the comparison with the rest of three models.

Fourteen biomass estimation options were considered to see the effect of application of depth-dependent TS. They are summarized in Table 1. For models (3) and (4), mean TS in each 1, 5, 10, 30 and $50 \mathrm{~m}$ depth bin from 0 to $150 \mathrm{~m}$ (but no data were available from 0 to $7 \mathrm{~m}$ ) were calculated. In addition, $T S$ at mean distribution depth of Japanese anchovy was also calculated by using models (3) and (4). Uncertainties of the biomasses were estimated by using methods described in a reference [13].

\section{RESULTS}

A total of 1,479 n.miles of acoustic data were recorded along the tracklines in the survey area $\left(131,047\right.$ n.mile $\left.{ }^{2}\right)$. The trawl was towed at 21 stations. Because Japanese anchovy 
Table 1. Fourteen biomass estimation options considered in the analysis to see the effect of application of depthdependent $T S . T S$ models referred in the table are as follows: (1) $T S=20 \log L_{t}-71.9$ [6], (2) $T S=20 \log L_{t}-72.5$ [12], (3) $T S=20 \log L_{t}-(20 / 3) \log (1+z / 10)-67.6[31]$ and (4) $T S=20 \log L_{t}(20 / 3) \log (1+z / 10)-64.7[1]$, where $L_{t}$ is total length $(\mathrm{cm})$ and $z$ is water depth $(\mathrm{m})$ corresponding to distribution of Japanese anchovy.

\begin{tabular}{|c|c|c|c|c|}
\hline Name of option & TS model & Depth-dependence & Depth considered in calculation & Pitch angle \\
\hline$(1)$ & $(1)$ & \multirow{2}{*}{$\mathrm{N}$} & \multirow{2}{*}{-} & \multirow{8}{*}{-} \\
\hline$(2)$ & $(2)$ & & & \\
\hline (3)-mean & \multirow{6}{*}{ (3) } & \multirow{12}{*}{ Y } & mean distribution depth $(23 \mathrm{~m})$ & \\
\hline (3)-1 m & & & $1 \mathrm{~m}$ bin & \\
\hline (3) $-5 \mathrm{~m}$ & & & $5 \mathrm{~m}$ bin & \\
\hline (3)-10 m & & & $10 \mathrm{~m}$ bin & \\
\hline (3) $-30 \mathrm{~m}$ & & & $30 \mathrm{~m}$ bin & \\
\hline (3) $-50 \mathrm{~m}$ & & & $50 \mathrm{~m}$ bin & \\
\hline (4)-mean & \multirow{6}{*}{ (4) } & & mean distribution depth $(23 \mathrm{~m})$ & \multirow{6}{*}{$0^{\circ} \pm 10^{\circ} \mathrm{stc}$} \\
\hline (4)-1 m & & & $1 \mathrm{~m}$ bin & \\
\hline (4)-5 m & & & $5 \mathrm{~m}$ bin & \\
\hline (4)-10 m & & & $10 \mathrm{~m}$ bin & \\
\hline (4)-30 m & & & $30 \mathrm{~m}$ bin & \\
\hline (4) $-50 \mathrm{~m}$ & & & $50 \mathrm{~m}$ bin & \\
\hline
\end{tabular}

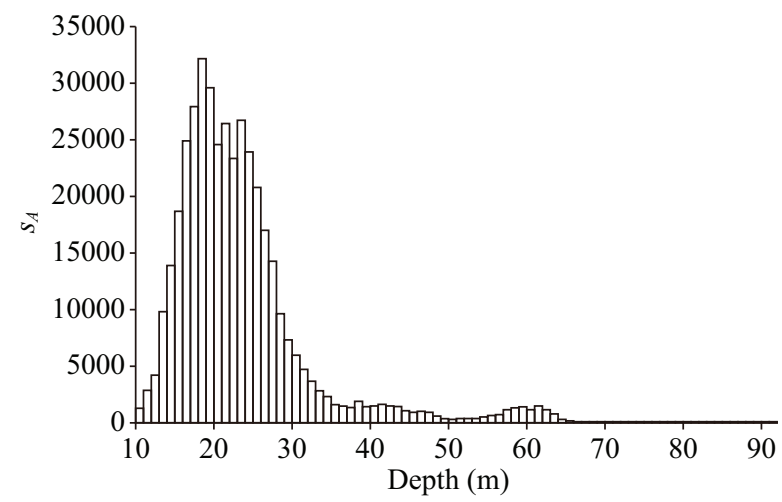

Fig. 2. Vertical distribution pattern of Japanese anchovy by $1 \mathrm{~m}$ depth bin. Mean distribution depth $=23 \mathrm{~m}$. Density of Japanese anchovy is expressed as $s_{A}$.

was dominant pelagic fish species $(98 \%$ of total catch in wet weight), all backscatterings classified as pelagic fish were considered as Japanese anchovy in this analysis. Mean $L_{t}$ and the corresponding $W_{t}$ of Japanese anchovy in the survey area was $13.4 \mathrm{~cm}(\mathrm{CV}=0.13)$ and $14.2 \mathrm{~g}$, respectively. Vertical distribution pattern of Japanese anchovy is shown in Fig. 2. Mean and maximum distribution depth was $23(\mathrm{CV}=0.39)$ and $91 \mathrm{~m}$, respectively. Horizontal distribution pattern of Japanese anchovy is shown in Fig. 3.

Estimated biomasses based on 6 calculation options by using model (3) are shown in Table 2. There was no significant difference among the options. The biomass estimates by using $T S$ in $1 \mathrm{~m}$ bin and $T S$ at the mean distribution depth were comparable. Estimated biomasses based on 6 calculation options by using model (4) are shown in Table 3. As in the case

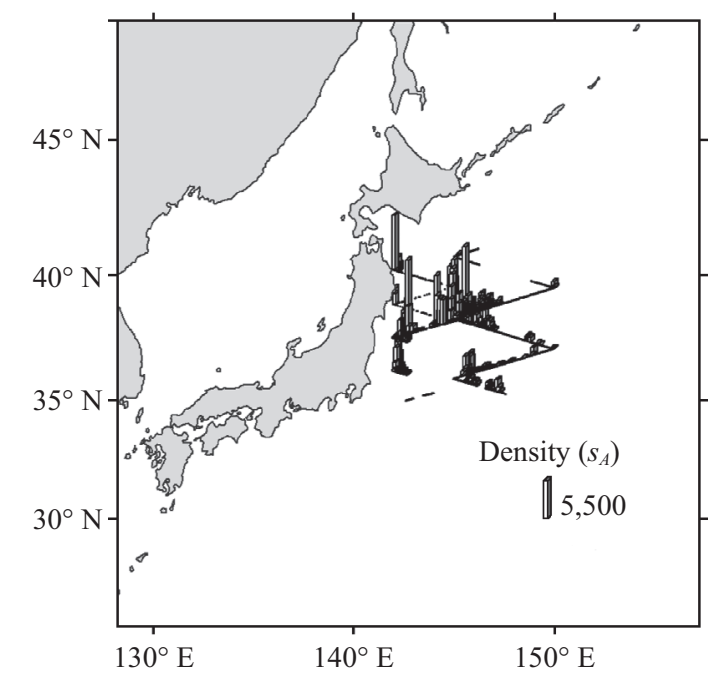

Fig. 3. Surveyed trackline and horizontal distribution pattern of Japanese anchovy. Density is expressed as nautical area scattering coefficient $\left(\mathrm{m}^{2} / \mathrm{n} \cdot \mathrm{mile}^{2}, s_{A}\right)$.

of model (3), there was no significant difference among the options. The biomass estimates by using $T S$ in $1 \mathrm{~m}$ bin and $T S$ at the mean distribution depth were also comparable.

Biomasses estimated by models (1)-(4) are shown in Table 4. Biomass estimate by model (3) was 82 and $73 \%$ of biomass estimates by models (1) and (2), respectively. Biomass estimate by model (3) was $195 \%$ of model (4).

\section{DISCUSSION}

$T S$ of Japanese anchovy in each $1 \mathrm{~m}$ bin calculated by 
Table 2. Estimated biomasses of Japanese anchovy by using a $T S$ model: $T S=20 \log L_{t}-(20 / 3) \log (1+z / 10)-67.6[31]$. Six options are considered with this model.

\begin{tabular}{ccccccc}
\hline Options & (3)-mean & (3)-1 m & (3)-5 m & (3)-10 m & (3)-30 m & (3)-50 m \\
\hline Mean density (t/n.mile $^{2}$ ) & 22.83 & 22.66 & 22.43 & 22.43 & 22.21 & 24.96 \\
Biomass (million t) & 2.99 & 2.97 & 2.94 & 2.94 & 2.91 & 3.27 \\
CV (million t) & 0.29 & 0.31 & 0.31 & 0.31 & 0.30 & 0.30 \\
\hline
\end{tabular}

Table 3. Estimated biomasses of Japanese anchovy by using a $T S$ model: $T S=\log L_{t}-(20 / 3) \log (1+z / 10)-64.7$ [1]. Six options are considered with this model.

\begin{tabular}{ccccccc}
\hline Options & (4)-Mean & $(4)-1 \mathrm{~m}$ & $(4)-5 \mathrm{~m}$ & $(4)-10 \mathrm{~m}$ & $(4)-30 \mathrm{~m}$ & $(4)-50 \mathrm{~m}$ \\
\hline Weighted mean $\rho$ (t/n.mile $\left.{ }^{2}\right)$ & 11.71 & 11.62 & 11.50 & 11.50 & 11.39 & 12.80 \\
Biomass (million $\mathrm{t})$ & 1.53 & 1.52 & 1.51 & 1.51 & 1.49 & 1.68 \\
CV (million $\mathrm{t})$ & 0.29 & 0.31 & 0.31 & 0.31 & 0.30 & 0.30 \\
\hline
\end{tabular}

Table 4. Estimated biomasses of Japanese anchovy by using 4 different $T S$ models.

\begin{tabular}{ccccc}
\hline Options & $(1)$ & $(2)$ & (3)-mean & (4)-mean \\
\hline Mean density (t/n.mile $\left.{ }^{2}\right)$ & 27.73 & 31.33 & 22.83 & 11.71 \\
Biomass (million t) & 3.63 & 4.11 & 2.99 & 1.53 \\
CV (million t) & 0.29 & 0.29 & 0.29 & 0.29 \\
\hline
\end{tabular}

models (3) and (4) can be considered as actual TS observed in a natural condition. However, this study revealed that biomass estimates by using TS at mean distribution depth was comparable with biomass estimates by using $T S$ in each $1 \mathrm{~m}$ bin. The results implicated that analysis task would be reduced if $T S$ at mean distribution depth was used. The finding is helpful for an analyst who deals with huge amount of acoustic data in routine manner. Because the results were inferred from a single survey, further studies by using different data sets are helpful to investigate whether the results of this paper is applicable globally.

Biomass estimate by model (3) was reduced to 82 and $73 \%$ of biomass estimates by models (1) and (2). The results sugested that biomass estimates by using $T S$ without consideration of depth-dependence (models (1) and (2)) were overestimated given mean distribution depth of $23 \mathrm{~m}$. Use of depth-dependent $T S$ is recommended in the future analysis.

However, the results of this study also suggested that effect of pitch angle on biomass estimation could not be negligible even if depth-dependent TS was taken account. Model (3) was based on in-situ data collected in nighttime in the Yellow Sea while a survey vessel steamed at constant speed ( 10 knots). Because data were collected in-situ, pitch angle of Japanese anchovy was not known in model (3). Model (3) can be considered as $T S$ under a condition of a routine acoustic biomass estimation survey in nighttime.

Amakasu et al. [1] investigated the effect of change in pitch angles other than $\left(0^{\circ}, 10^{\circ}\right)$ : $\left(10.3^{\circ}, 20.3^{\circ}\right)$ and $\left(-1.3^{\circ}, 20.8^{\circ}\right)$.
The former pitch angle was recorded by a still camera [2] while the later was recorded by a stereo video camera [22]. Both were measured in nighttime. These two values can be considered as pitch angles of Japanese anchovy in undisturbed natural states in nighttime. The pitch angle in daytime may be different from that in nighttime. However, the pitch angle in daytime has not been reported in scientific literature.

Several studies demonstrated that clupeoids showed vertical avoidance behavior to approaching vessels: round sardinella (Sardinella aurita) in Venezuela [9], Peruvian anchovy (Engraulis ringens) and Araucanian herring (Strangomera bentincki) in Chile [8] and unspecified species of anchovy in California [4]. It was observed that $s_{A}$ of Peruvian anchovy and Araucanian herring decreased near the transducer [8]. Gerlotto et al. [8] suggested that decrease in $s_{A}$ near the transducer could be results of vertical avoidance. Similar decrease in $s_{A}$ of Japanese anchovy near the transducer was also observed in this study as shown in Fig. 2. The figure might indicate a possibility of vertical avoidance of Japanese anchovy though no conclusion can not be drawn from the results at this stage.

A peak of $T S$ of Japanese anchovy based on a Kirchoff-ray-mode (KRM) model [3] was observed at a pitch angle of $-5.2^{\circ}[1]$. The $T S$ was decreased as the pitch angle was away from the value. If Japanese anchovy shows descending vertical avoidance to approaching vessel, the pitch angle might be smaller than values observed in undisturbed natural states. Therefore, there is a possibility that the TS might be small than values in undisturbed natural states.

Even though understanding of the pitch angle under a condition of acoustic biomass estimation survey is important for an abundance/biomass estimation using a vertically oriented echosounder, it is difficult to estimate it in-situ by using conventional methods. A combination of net and/or optical sampling of target species with newly developing acoustic devices such as a broadband [11], and/or a multibeam sonar [4] can be one of the alternative methods in the future study. 
Use of model (3) which was measured in-situ might be reasonable for time being. However, it is difficult to select the best TS model of Japanese anchovy based thoroughly on the results of this paper. Comparison between in-situ TS data recorded by a vertically oriented echosounder and the $T S$ models considered in this paper would be a method to select the best $T S$ model of Japanese anchovy in the future study.

In this paper, it was assumed that species composition in water depth deeper than $20 \mathrm{~m}$ was same as it was in water depth less than $20 \mathrm{~m}$. It is believed that the assumption is not far from the true species composition based on expert knowledge of the authors of this paper. However, the validity is in question because of lack of data to support it. Vertical distribution patterns of pelagic fishes in the survey area should be study to validate the assumption.

\section{ACKNOWLEDGMENTS}

We express thanks to all of the researchers and crews who were engaged in the survey. Comments from two anonymous reviewers and the guest editor, Dr. Masahiko Furusawa, greatly improved the contents of the manuscript. This survey was supported by the Fisheries Agency of Japan, the Fisheries Research Agency of Japan and the Institute of Cetacean Research. We thank these institutions for their support. The results of this paper was initially presented to the Asian Fisheries Acoustics Society (AFAS) 2009 meeting "The International Conference on Fisheries Acoustics and Contribution for Sustainable Fisheries in Asia". We express thanks to the conveners of the meeting who provided us such opportunity.

\section{REFERENCES}

1. Amakasu, K., Sadayasu, K., Abe, K., Takao, Y., Sawada, K., and Ishii, K., "Swimbladder shape and relationship between target strength and body length of Japanese anchovy (Engraulis japonicus)," Journal of the Marine Acoustics Society of Japan, Vol. 37, No. 1, pp. $46-59$ (2010). (in Japanese with English abstract)

2. Aoki, I. and Inagaki, T., "Photographic observations on the behaviour of Japanese anchovy Engraulis japonica at night in the sea" Marine Ecology Progress Series, Vol. 43, pp. 213-221 (1988).

3. Clay, C. S. and Horne, J. K., "Acoustic models of fish: The Atlantic cod (Gadus morhua)," Journal of the Acoustical Society of America, Vol. 96, No. 3, pp. 1661-1668 (1994).

4. Cutter, G. R., Jr. and Demer, D. A., "Accounting for scattering directivity and fish behaviour in multibeam-echosounder surveys," ICES Journal of Marine Science, Vol. 64, No. 9, pp. 1664-1674 (2007).

5. FAO, FAO Yearbook, Fishery and Aquaculture Statistics 2007, FAO, Rome (2009)

6. Foote, K. G., "Fish target strengths for use in echo integrator surveys," Journal of Acoustical Society of America, Vol. 82, No. 3, pp. 981-987 (1987).

7. Fujino, T., Kawabata, A., and Kidokoro, H., Echograms of Aquatic Organisms Observed by a Quatitative Echosounder around Japan, Japan Sea National Fisheries Research Institute, Niigata (2010). (in Japanese)

8. Gerlotto, F., Castillo, J., Saavedra, A., Barbieri, M. A., Espejo, M., and Cotel, P., "Three-dimensional structure and avoidance behaviour of anchovy and common sardine schools in central southern Chile," ICES Journal of Marine Science, Vol. 61, No. 7, pp. 1120-1126 (2004).
9. Gerlotto, F. and Fréon, P., "Some elements on vertical avoidance of fish schools to a vessel during acoustic surveys," Fisheries Research, Vol. 14, No. 4, pp. 251-259 (1992).

10. Gorska, N. and Ona, E., "Modelling the acoustic effect of swimbladder compression in herring," ICES Journal of Marine Science, Vol. 60, No. 3, pp. 548-554 (2003).

11. Imaizumi, T., Furusawa, M., Akamatsu, T., and Nishimori, Y., "Measuring the target strength spectra of fish using dolphin-like short broadband sonar signals," Journal of the Acoustical Society of America, Vol. 124, No. 6, pp. 3440-3449 (2008).

12. Iversen, S. A., Zhu, D., Johannesen, A., and Toresen, R., "Stock size, distribution and biology of anchovy in the Yellow Sea and East China Sea," Fisheries Research, Vol. 16, No. 2, pp. 147-163 (1993).

13. Jolly, G. M. and Hampton, I., "A stratified random transect design for acoustic surveys of fish stocks," Canadian Journal of Fisheries and Aquatic Sciences, Vol. 47, No. 7, pp. 1282-1291 (1990).

14. Murase, H., Ichihara, M., Yasuma, H., Watanabe, H., Yonezaki, S., Nagashima, H., Kawahara, S., and Miyashita, K., "Acoustic characterization of biological backscatterings in the Kuroshio-Oyashio inter-frontal zone and subarctic waters of the western North Pacific in spring," Fisheries Oceanography, Vol. 18, No. 6, pp. 386-401 (2009).

15. Murase, H., Nagashima, H., Yonezaki, S., Matsukura, R., and Kitakado, T., "Application of a generalized additive model (GAM) to reveal relationships between environmental factors and distributions of pelagic fish and krill: a case study in Sendai Bay, Japan," ICES Journal of Marine Science, Vol. 66, No. 6, pp. 1417-1424 (2009).

16. Murase, H., Tamura, T., Kiwada, H., Fujise, Y., Watanabe, H., Ohizumi, H., Yonezaki, S., Okamura, H., and Kawahara, S., "Prey selection of common minke (Balaenoptera acutorostrata) and Bryde's (Balaenoptera edeni) whales in the western North Pacific in 2000 and 2001," Fisheries Oceanography, Vol. 16, No. 2, pp. 186-201 (2007).

17. Nagashima, H., "Spatial distribution properties of pelagic fish school in Miyagi coastal waters," Miyagi Prefecture Report of Fisheries Science, Vol. 8, pp. 1-12 (2006). (in Japanese)

18. Ohshimo, S., "Acoustic estimation of biomass and school character of anchovy Engraulis japonicus in the East China Sea and the Yellow Sea," Fisheries Science, Vol. 62, No. 3, pp. 344-349 (1996).

19. Ohshimo, S., "Spatial distribution and biomass of pelagic fish in the East China Sea in summer, based on acoustic surveys from 1997 to 2001," Fisheries Science, Vol. 70, No. 3, pp. 389-400 (2004).

20. Ohshimo, S. and Hamatsu, T., "Vertical distribution and acoustic estimation of biomass of walleye pollock Theragra chalcogramma, and anchovy Engraulis japonicus in the Pacific coast of eastern Hokkaido," Bulletin of the Hokkaido National Fisheries Research Institute, Vol. 60, pp. 225-237 (1996).

21. Ona, E., "An expanded target-strength relationship for herring," ICES Journal of Marine Science, Vol. 60, No. 3, pp. 493-499 (2003).

22. Sawada, K., Takahashi, H., Abe, K., Ichii, T., Watanabe, K., and Takao, Y., "Target-strength, length, and tilt-angle measurements of Pacific saury (Cololabis saira) and Japanese anchovy (Engraulis japonicus) using an acoustic-optical system," ICES Journal of Marine Science, Vol. 66, No. 6, pp. 1212-1218 (2009).

23. Sunou, N., Yokosuka, I., and Nita, K., "Acoustic surveys of the Japanese anchovy, Engraulis japonica, in the waters off Joban and Kashimanada Sea Areas," Report of Ibaraki Prefectural Fisheries Experimental Station, Vol. 38, pp. 33-38 (2000). (in Japanese)

24. Takasuka, A., Oozeki, Y., Kimura, R., Kubota, H., and Aoki, I., "Growth-selective predation hypothesis revisited for larval anchovy in offshore waters: cannibalism by juveniles versus predation by skipjack tunas," Marine Ecology Progress Series, Vol. 278, pp. 297-302 (2004).

25. Tsukamoto, Y., Zenitani, H., Kimura, R., Watanabe, Y., and Oozeki, Y., "Vertical distribution of fish larvae in the Kuroshio and KuroshioOyashio transition region in early summer," Bulletin of the National Research Institute of Fisheries Science, Vol. 16, pp. 39-56 (2001).

26. Ueno, Y., Suyama, S., Kurita, Y., and Kumazawa, T., "Design and operation methods of a mid-water trawl for quantitative sampling of a surface 
pelagic fish, Pacific saury (Cololabis saira)," Fisheries Research, Vol. 66, No. 1, pp. 3-17 (2004).

27. Whitehead, P. J. P., Nelson, G. J., and Wongratana, T., FAO Species Catalogue. Vol. 7. Clupeoid Fishes of the World (Suborder Clupeoidei). An Annotated and Illustrated Catalogue of the Herrings, Sardines, Pilchards, Sprats, Anchovies and Wolf-herrings. Part 2. Engraulididae, FAO, Rome, pp. 305-529 (1988).

28. Yasugi, S., "Distinguish of pelagic fish stock by use of quantitative echo sounder and midwater trawl," Report of Shimane Prefectural Fisheries Experimental Station, Vol. 11, pp. 7-13 (2003). (in Japanese with English abstract)
29. Yatsu, A., Sassa, C., Moku, M., and Kinoshita, T., "Night-time vertical distribution and abundance of small epipelagic and mesopelagic fishes in the upper $100 \mathrm{~m}$ layer of the Kuroshio-Oyashio Transition Zone in Spring," Fisheries Science, Vol. 71, No. 6, pp. 1280-1286 (2005)

30. Zhao, X., "The acoustic survey of anchovy in the Yellow Sea in February 1999, with emphasis on the estimation of the size structure of the anchovy population," Marine Fisheries Research, Vol. 22, No. 4, pp. 40-44 (2001).

31. Zhao, X., Wang, Y., and Dai, F., "Depth-dependent target strength of anchovy (Engraulis japonicus) measured in situ," ICES Journal of Marine Science, Vol. 65, No. 6, pp. 882-888 (2008). 